\title{
FATORES CONTROLADORES DOS PROCESSOS DESNUDACIONAIS GEOQUÍMICOS NO ESPINHAÇO MERIDIONAL (DEPRESSÃO DE GOUVEIA, MG)
}

\author{
André Augusto Rodrigues Salgado (*) \& Roberto Célio Valadão (**)
}

\begin{abstract}
RESUMO
O presente trabalho investiga os fatores controladores dos processos desnudacionais geoquímicos na Depressão de Gouveia e seu entorno (Espinhaço Meridional/MG). Foram utilizadas análises físicoquímicas de águas superficiais coletadas em 21 (vinte e um) pontos de monitoramento, localizados em duas bacias hidrográficas que drenam a área de estudo. A coleta das amostras de água foi realizada em três períodos distintos do ano: seco, úmido e semi-úmido. Os parâmetros analisados foram: $\mathrm{pH}$, condutividade elétrica, sólidos totais dissolvidos, sílica, ferro, alumínio, sódio, cálcio, magnésio e potássio. Os resultados obtidos indicam que o arcabouço litoestrutural corresponde à principal variável ambiental capaz de explicar a dinâmica desnudacional geoquímica da área investigada, a qual é seguida, em grau de relevância, pelo débito do canal fluvial amostrado. Os resultados apontam ainda para a ocorrência de dois comportamentos desnudacionais geoquímicos distintos: (i) elevadas taxas de desnudação geoquímica naquelas áreas topograficamente deprimidas que ocupam o piso da Depressão de Gouveia, modelada nos litotipos arqueanos do Complexo Gouveia; (ii) baixas taxas de desnudação geoquímica notadamente nos planaltos que circundam essa depressão, modelados, sobretudo nas unidades quartzíticas do Supergrupo Espinhaço. A evolução geomorfológica da área investigada apresenta elementos preconizados em algumas teorias que tratam da evolução do modelado continental, embora não seja possível enquadrar, de forma inequívoca e absoluta, a evolução da área investigada em uma única dessas teorias.
\end{abstract}

\begin{abstract}
This paper is a research about the controls factors of chemical denudation process in Gouveia's Depression and around (Espinhaço Meridional/MG). The Gouveia's Depression is a depression on granites and a gneissic rock that has in it's around the Espinhaço Mountains that is on quartzite's rocks. The research is based in physical-chemical analysis of superficial water. Was checked 21 (twenty one) points in two rivers basins that draining this area. The water levy was in three periods of the year: humid, dry and semi-humid. The physical-chemical analysis was: $\mathrm{pH}$, electric conductivity, total load, $\mathrm{Fe}, \mathrm{Al}, \mathrm{Na}, \mathrm{Ca}, \mathrm{Mg}, \mathrm{K}$ and silica. The results show that the litology and the structure are the most important environment variables that can explains the denudation dynamic in the area. In second place is the water discharge of the rivers. The results show too that has two chemical denudations situations in the area:(i) highest in the depression and (ii) lowest in the around. The area's geomorphologic evolution has elements of many models of relief evolution, however cannot be explain by only one.
\end{abstract}

\section{INTRODUÇÃO}

A evolução do relevo continental tem sido abordada a partir de diferentes modelos geodinâmicos. A construção desses modelos teve início com W.M. Davis em 1898, sendo que, atualmente, verifica-se um número considerável dos mesmos na literatura geomorfológica. Esses modelos, na busca de elucidar a geodinâmica da epiderme terrestre, comumente apóiam-se em fatores de ordens geomorfológica e geotectônica. Alguns modelos são predominantemente mecanicistas, a exemplo daquele elaborado por King (1953). Outros, concedem maior participação aos processos geoquímicos, a exemplo do modelo de etchplanação (Thomas, 1994 a,b). Alguns modelos utilizam abordagem essencialmente climática na explicação acerca da gênese das formas - Tardy (1969) -, embora outros reconheçam nas variações estruturais os fatores controladores dos processos desnudacionais - Penck (1924, in Summerfield, 1991). Podemos mesmo relacionar modelos em que a pedogênese assume fundamental importância na elaboração do modelado continental - Millot (1980). 
A proliferação de teorias acerca da evolução da epiderme terrestre, por vezes, dificulta a compreensão dos verdadeiros fatores que interferem na evolução do modelado (Valadão, 1998). Tal fato ocorre em virtude de que muitos pesquisadores encontram-se filiados a determinadas linhas de pensamento que, necessariamente, não são as mais adequadas para elucidar a dinâmica geomorfológica de uma dada região. Sendo assim, torna-se necessário investigar a geodinâmica de uma área de forma desvinculada de qualquer teoria, para, somente após analisar os resultados obtidos, verificar se a evolução da região investigada se adequa a alguma dessas correntes de pensamento.

É nesse contexto que se insere o presente trabalho, cujo objetivo é investigar os fatores controladores da desnudação geoquímica na Serra do Espinhaço Meridional, particularmente na região da Depressão de Gouveia e no seu entorno.

\section{PROCEDIMENTOS METODOLÓGICOS}

Tendo em vista cumprir o objetivo proposto, foram analisadas as taxas de desnudação geoquímica de duas bacias hidrográficas que drenam a Depressão de Gouveia: (i) Bacia do Córrego Rio Grande, que ocupa área de 34,04 km² (Figura 1); (ii) Bacia do Ribeirão Areia, a montante de sua confluência com o Ribeirão do Chiqueiro, com área de 134,00 km² (Figura 2). Na Bacia do Córrego do Rio Grande foram monitorados 9 (nove) pontos de coleta de água para análises hidroquímicas. Já na Bacia do Ribeirão Areia esse total alcançou 12 (doze). A localização dos pontos para monitoramento visou amostrar a maior diversidade geoambiental das áreas de montante, visto que ambas as bacias possuem parte de sua área localizada no interior da Depressão de Gouveia, bem como parte localizada sobre os quartzitos da Serra do Espinhaço, unidade geomorfológica que circunda essa depressão.

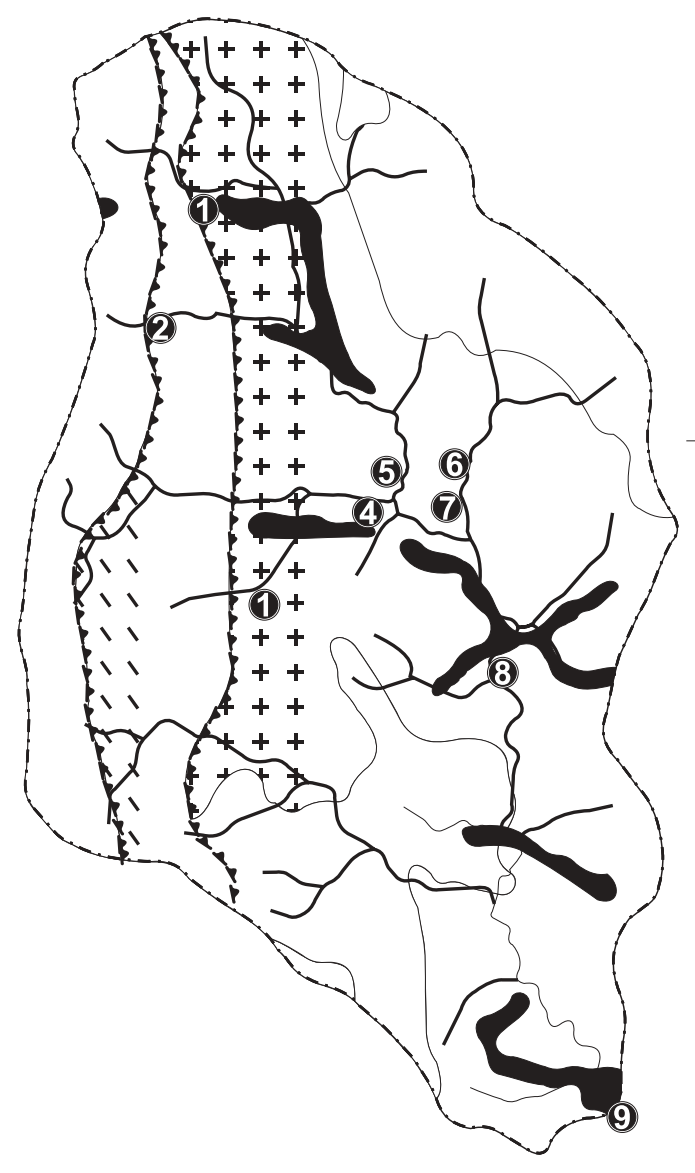

(3) Ponto de amostragem

Rede Hidrográfica

-. Limite de Bacia

Linha de Escarpas

응 읨 Diques e soleiras de metabásicas intrusivas (metadiabásios e metagabros) tarde-tectônicas (pós-Espinhaço)

ถุต

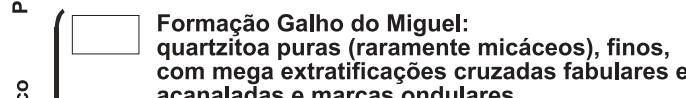
acanaladas e marcas ondulares

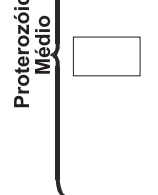

Formação São João da Chapada:

quartzitos médios, bimodais, com extratificação cruzada tabular e acanalada, contendo um nível basal de metabrechas e metaconglomerados polimíticos, ao qual se superpõe um horizonte sin-sedimentar de vulcãnicas de filiação básica (filítos hematíticos e subordinadamente xistos verdes).

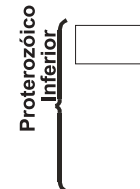

Grupo Costa Sena:

quartzo xistos, quartzo mica-xistos com ou sem sianita, clorita quartzo-xistos, localmente com formação ferrífera e metavulcanitos ácidos (Formação Barão de Guaicuí) com passagens gradacionais para quartzitos micácios de metaconglomerado de polimíctico (Formação Bandeirinha).
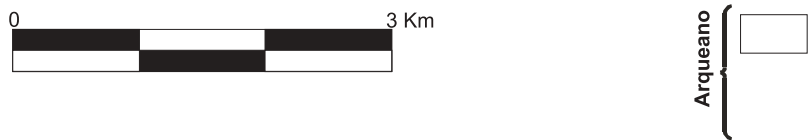

Compléxo de Gouveia:

associação de rochas graníticas senso lato (granodioritos, monzogranitos,) predominand sobre migmatítos e anfibolitos. Em faixas cisalhadas ocorrem protomilonitos, milonitos ultramilonitos e filonitos.

Fonte: Carta Geológica Folhas Diamantina e Presidente Kubitschek 1: 100.000 COMIG - MG 1996 Draw by Mario Emmanuel, Valéria Barbosa, Saul Silva e Ricardo Guimarães

Figura 1- Pontos de amostragem e Geologia da Bacia do Córrego Rio Grande. 


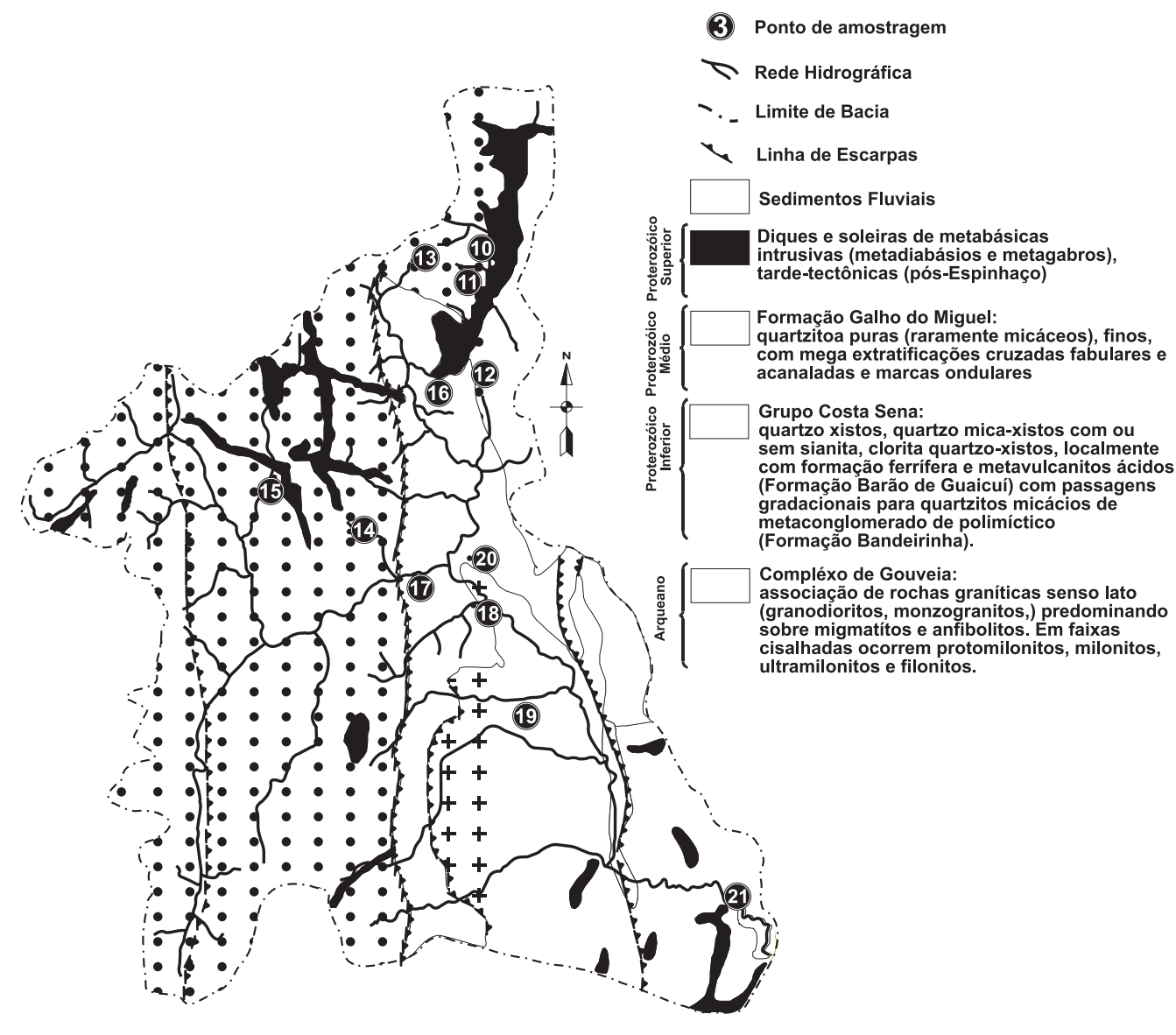

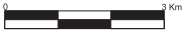

Fonte: Carta Geológica Folhas Diamantina e Presidente Kubitschek 1: 100.000 COMIG - MG 1996 Draw by Mario Emmanuel, Valéria Barbosa, Saul Silva e Ricardo Guimarães
\end{abstract}

Figura 2- Pontos de amostragem e Geologia da Bacia do Ribeirão Areia.

O procedimento metodológico adotado teve início com a elaboração e a análise integrada de mapas temáticos referentes às duas bacias hidrográficas investigadas - mapas de declividade, compartimentação altimétrica, amplitude do relevo, vazão dos canais fluviais e arcabouço geológico -, seguidas pela análise dos resultados egressos das análises hidroquímicas realizadas em canais fluviais de ordens hierárquicas diversas, distribuídos em 21 pontos de monitoramento $\mathrm{pH}$, condutividade elétrica, sólidos totais dissolvidos, sílica, ferro, alumínio, sódio, cálcio, magnésio e potássio. As análises hidroquímicas foram executadas, segundo normas analíticas internacionais, nos laboratórios do Centro de Desenvolvimento de Tecnologia Nuclear (CDTN), em Belo Horizonte/MG. Os pontos de monitoramento tiveram suas águas amostradas ao longo do período de 1 (um) ano, notadamente nas estações climáticas semi-úmida (novembro/2000), úmida (março/ 2001) e seca (julho/2001). Contudo, nesse trabalho, só são apresentados os resultados relativos à sílica e aos sólidos totais dissolvidos, uma vez que esses se mostraram mais significativos e representativos para a elucidação dos fatores controladores da desnudação geoquímica na Depressão de Gouveia e entorno.

\section{CARACTERIZAÇÃODAÁREAINVESTIGADA}

A Depressão de Gouveia está localizada na porção central do Estado de Minas Gerais, entre os paralelos $18^{\circ} 20^{\prime}-18^{\circ} 30^{\prime} \mathrm{S}$ e os meridianos $43^{\circ} 40^{\prime}-43^{\circ} 50^{\prime} \mathrm{W}$. É circundada, em todas as direções, pelas escarpas quartzíticas da Serra do Espinhaço Meridional. Essas escarpas delimitam dois compartimentos geomorfológicos distintos: (i) o piso da depressão e (ii) a superficie de cimeira.

O piso da depressão é modelado nas rochas do embasamento arqueano, geologicamente denominado Complexo Gouveia. Litologicamente predominam granitos e gnaisses, embora seja comum a ocorrência de intrusões metabásicas datadas do proterozóico superior. Essas intrusões afloram em eixo NNW/SSE, orientação preferencial do sistema regional de falhas e fraturas. Morfologicamente esse compartimento é modelado em vertentes convexas alongadas, cujos 
interflúvios ocupam cotas altimétricas entre 1000 a 1050 m. O clima da área é tropical semi-úmido, com estação seca no inverno. Pedologicamente predominam latossolos que sustentam vegetação de cerrado bastante degradado. Destaca-se, na paisagem desse compartimento, grande quantidade de formas erosivas, principalmente voçorocas (Salgado, 2002).

O compartimento denominado superficie de cimeira tem como substrato predominante os quartzitos do Supergrupo Espinhaço. De modo semelhante ao piso da depressão, esses quartzitos são entrecortados por intrusões de rochas metabásicas. A morfologia típica desse compartimento é de uma superfície aplanada 1.250 a $1.300 \mathrm{~m}$-, que trunca, indiferentemente, dobramentos e cavalgamentos estruturados em quartzitos. Essa superfície é ainda pontilhada de relevos residuais, que se elevam a mais de $1.400 \mathrm{~m}$ de altitude. Os solos são rasos e arenosos, localmente litólicos. Variações pedológicas significativas ocorrem apenas nas áreas onde se encontram exumadas os litotipos pertencentes às intrusões de metabásicas, onde predominam latossolos. A vegetação é composta por estrato herbáceo, típico de campos de altitude.

As escarpas quartzíticas, que definem o contato entre esses dois compartimentos geomorfológicos, são modeladas nas rochas do Grupo Costa Sena e do Supergrupo Espinhaço. Apresentam declividade elevada e se estendem, geralmente, entre as cotas de 1.050 e $1.250 \mathrm{~m}$.

\section{ANÁLISE DOS DADOS}

As análises laboratoriais mostraram que, dentre os pontos de coleta de água monitorados, aqueles localizados no compartimento piso da depressão, onde afloram as unidades litológicas do Complexo Gouveia, caracterizam-se pela maior intensidade nos processos de desnudação geoquímica. Por outro lado, nos pontos localizados sobre o compartimento superficie de cimeira, a desnudação geoquímica é menos intensa. Comportamento mediano só foi observado nos pontos que, apesar de se situarem sobre os quartzitos, estão localizados sobre sistemas de falhas e fraturas.

Essas considerações são sustentadas pela análise da relação entre as unidades litológicas das bacias hidrográficas investigadas e a taxa média anual dos sólidos totais dissolvidos (Figura 3). A análise dessa figura permite verificar que, dentre os pontos amostrados, aqueles localizados sobre os litotipos do Complexo Gouveia apresentam as maiores taxas de desnudação geoquímica, ao passo que aqueles localizados sobre os quartzitos do Supergrupo Espinhaço - notadamente sobre a Formação Galho do Miguel - apresentam taxas mais reduzidas. O comportamento da taxa média anual de sílica, elemento mais desnudado geoquimicamente na área investigada, ratifica essa relação, visto que, a quantidade de sílica presente nas águas que drenam o embasamento é sempre mais elevada que aquela mensurada em seu entorno (Figura 4).
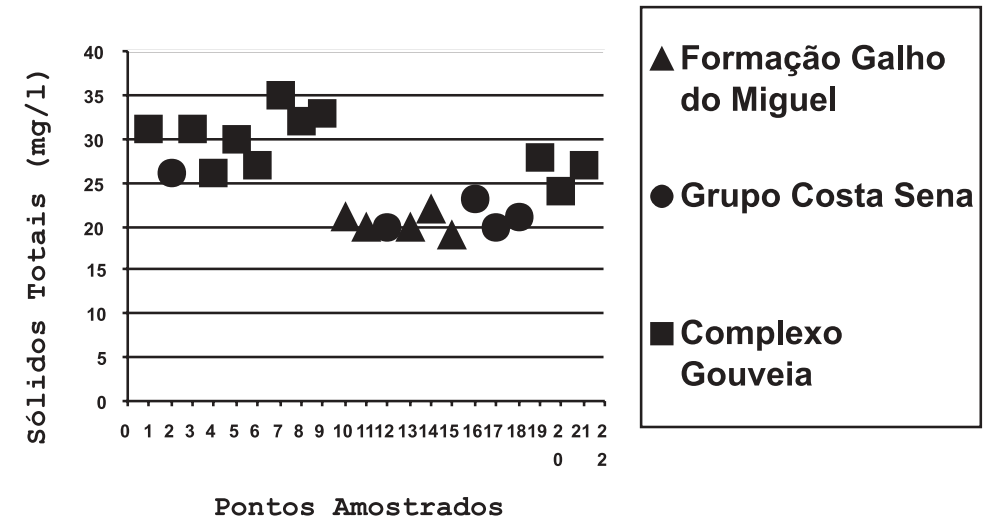

Pontos Amostrados

Figura 3- Variação das taxas anuais de sólidos totais dissolvidos segundo unidades litológicas.

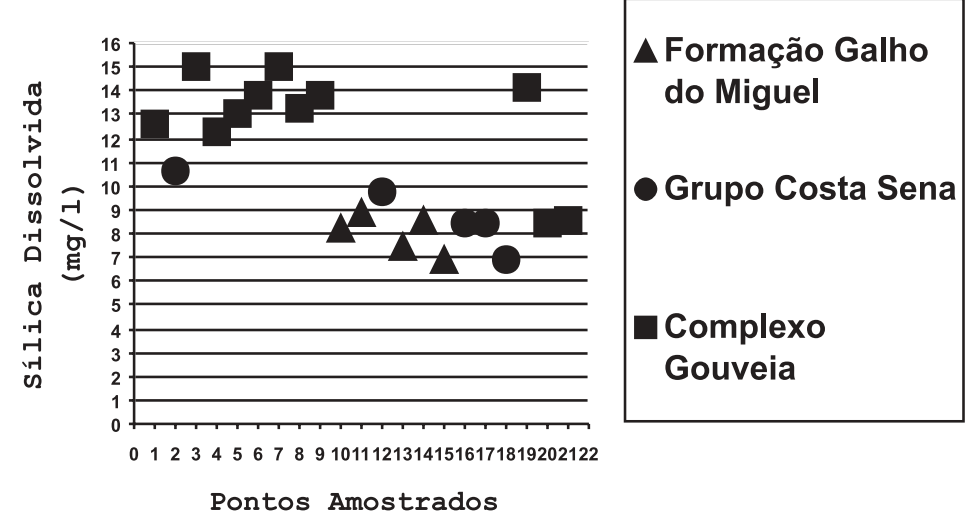

Figura 4- Variação das taxas anuais de sílica dissolvida segundo unidades litológicas. 
A declividade, a compartimentação altimétrica notadamente a cota altimétrica do ponto amostrado - e a amplitude do relevo - diferença de cota entre os pontos de maior e menor altimetria de cada sub-bacia - interferem de modo pouco significativo na composição físico- química da água dos canais fluviais amostrados. Comprova-se este fato verificando-se a ausência de relação clara e direta entre esses componentes ambientais com a variação nas taxas de elementos dissolvidos nas águas amostradas (figuras 5, 6, 7, 8, 9 e 10).

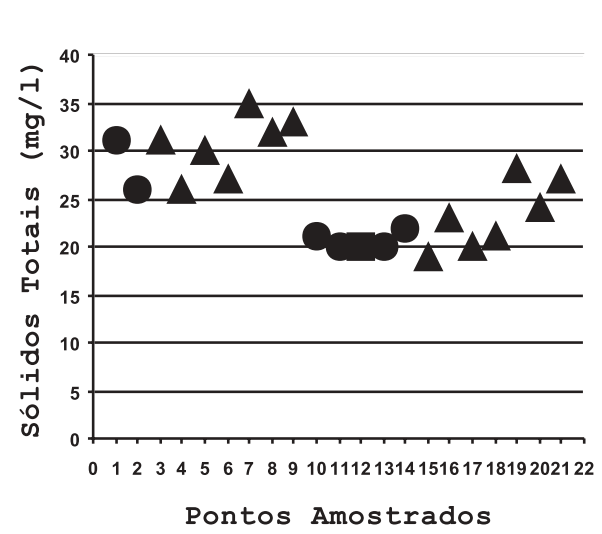

$\Delta$ Menos de $5 \%$

De 5 a $30 \%$

Mais de $30 \%$

Figura 5- Variação das taxas anuais de sólidos totais dissolvidos segundo classes de declividade.
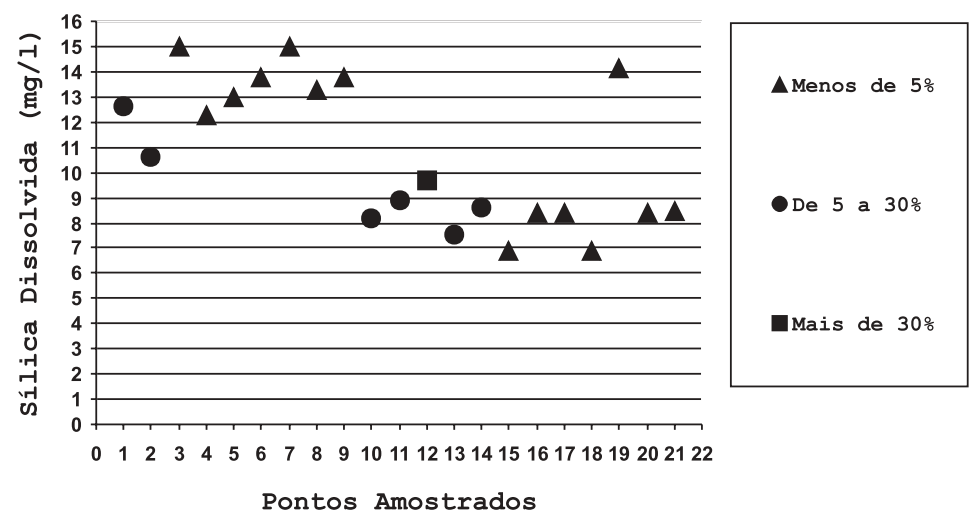

Amostrado

Figura 6- Variação das taxas anuais de sílica dissolvida segundo classes de declividade.

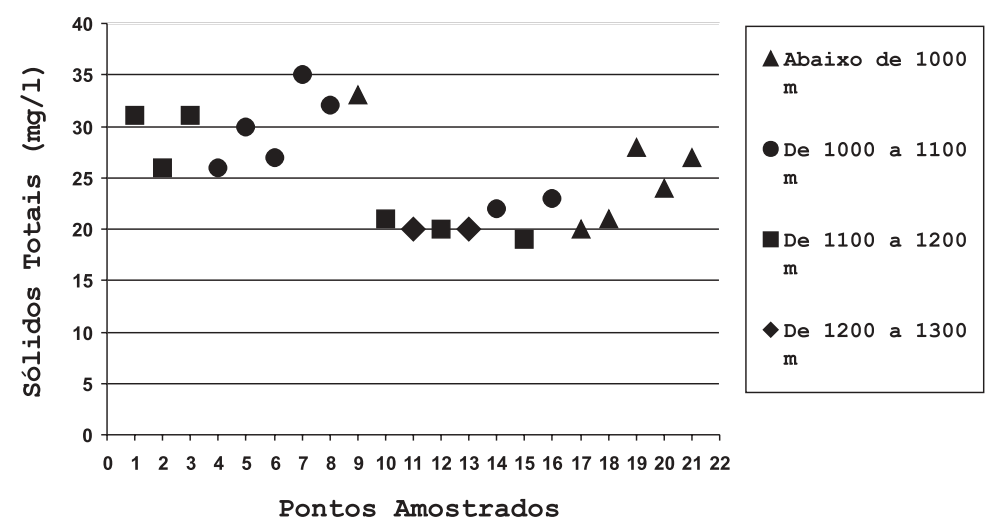

Figura 7- Variação das taxas anuais de sólidos totais dissolvidos segundo compartimentação altimétrica. 

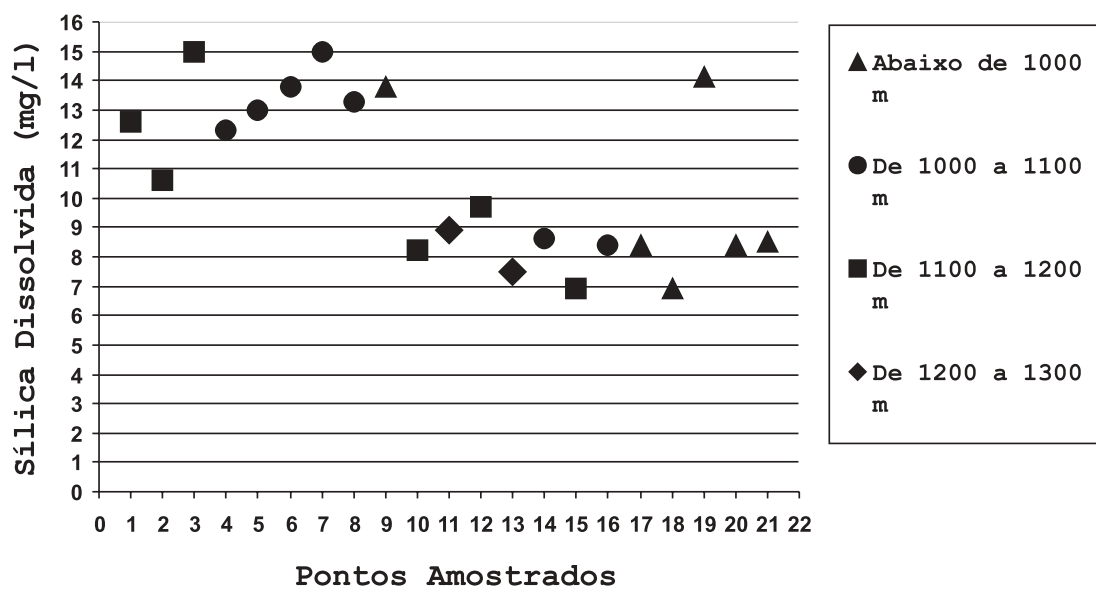

Figura 8-Variação das taxas anuais de sílica dissolvida segundo compartimentação altimétrica.

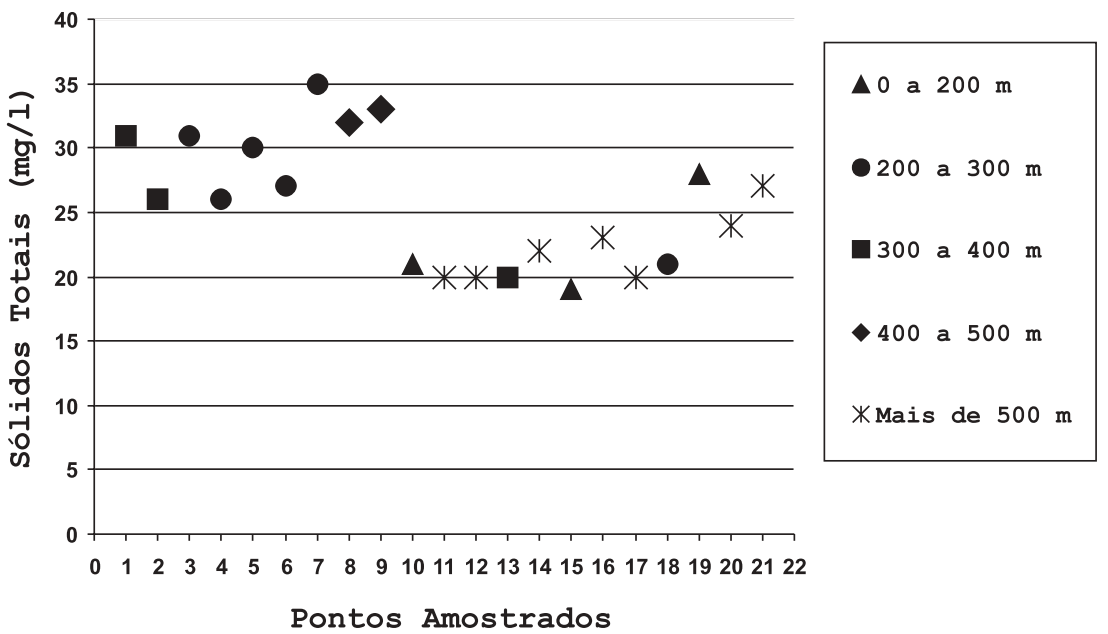

Figura 9- Variação das taxas anuais de sólidos totais dissolvidos segundo amplitude do relevo.

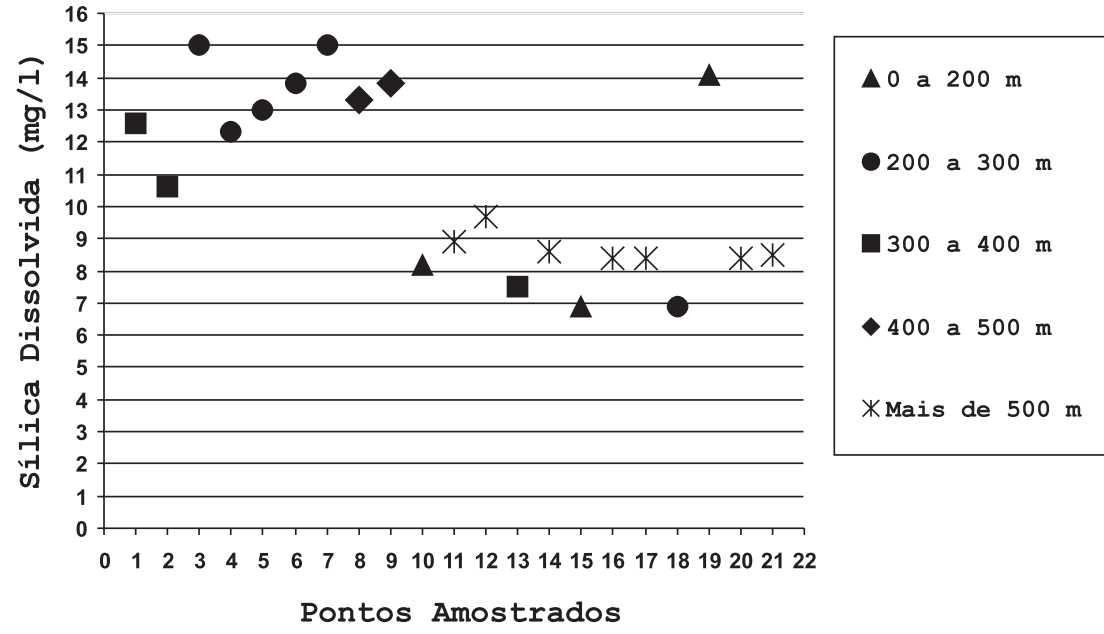

Figura 10- Variação das taxas anuais de sílica dissolvida segundo compartimentação altimétrica.

Por outro lado, a vazão do canal fluvial, no ponto amostrado, interfere de modo significativo na intensidade da desnudação geoquímica. Canais fluviais com vazão elevada, apesar de apresentarem concentrações de elementos químicos por vezes diluídas, tendem, graças ao seu maior volume, a desnudar mais intensamente que canais fluviais de vazão mais reduzida. Entretanto, a interferência da vazão não se apresenta de forma tão significativa quanto àquela da litoestrutura, ou seja, canais fluviais de vazão alta, que drenam sobretudo quartzitos, desnudam mais lentamente que aqueles de vazão baixa, cuja rede hidrográfica drena litotipos do embasamento. Alguns pontos monitorados, apesar de apresentarem vazão alta, não apresentam taxas de elementos dissolvidos diluídas. Isto ocorre geralmente naqueles pontos localizados no piso da depressão, sugerindo, mais uma vez, um controle predominantemente litoestrutural na intensidade da desnudação geoquímica, como mostrado nas figuras $11 \mathrm{e} 12$. 


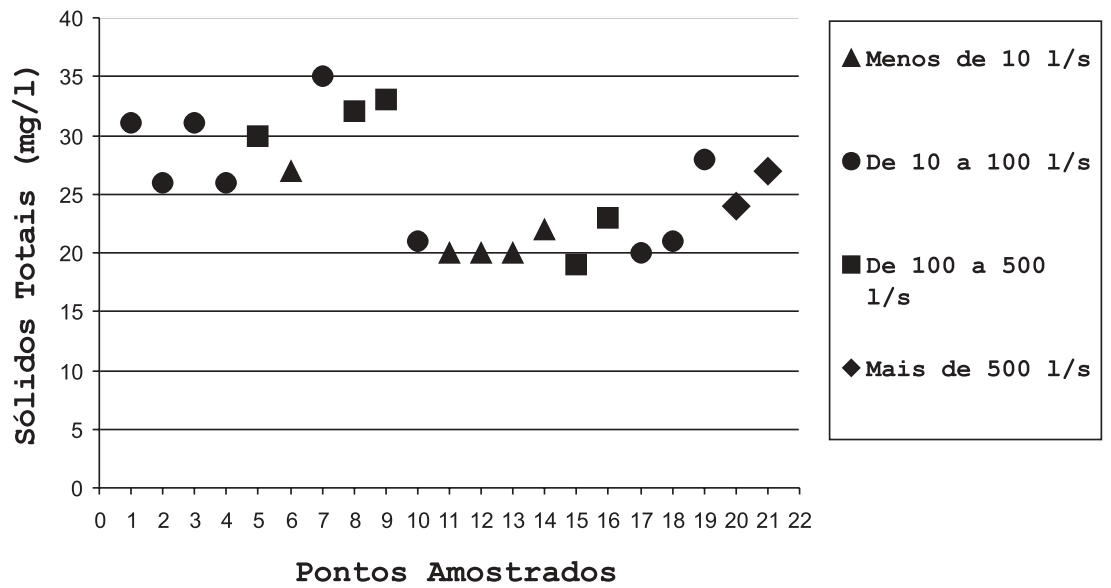

Figura 11-Variação das taxas anuais de sólidos totais dissolvidos segundo classes de vazão em l/s.

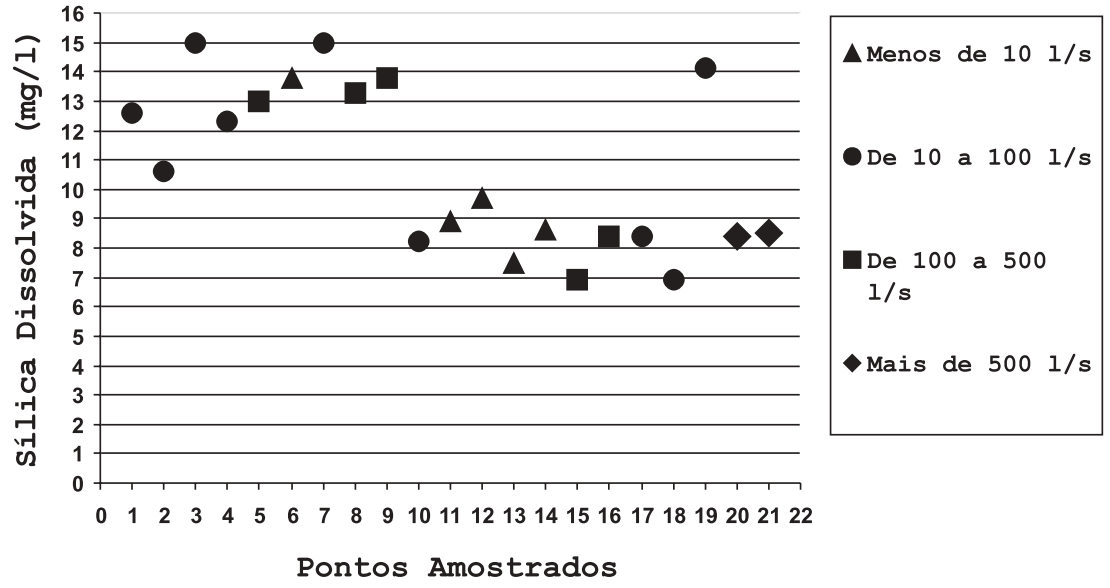

Figura 12- Variação das taxas anuais de sílica dissolvida segundo classes de vazão em $\mathrm{l} / \mathrm{s}$.

\section{CONSIDERAÇÕES FINAIS}

A análise dos dados comprova que o fator determinante na composição físico-química das amostras de água investigadas está diretamente correlacionado a litoestrutura presente à montante do ponto de amostragem. Os quartzitos que ocorrem no compartimento da superfície de cimeira apresentam grande resistência a desnudação geoquímica. Todavia, o piso da depressão, modelado nas litologias do Complexo Gouveia, caracteriza-se pela desnudação geoquímica elevada. Taxas medianas só ocorrem naqueles pontos que tem por substrato os litotipos quartzíticos e estão localizados sobre sistemas preferenciais de falhas e fraturas. A vazão do ponto amostrado interfere na taxa dos elementos dissolvidos, embora essa influência seja sensivelmente menor que aquela correlacionada a litoestrutura.

A comparação dos resultados alcançados com as teorias que tratam da evolução do relevo continental sugere que, na área investigada, as teorias estruturalistas explicam melhor a evolução do relevo que aquelas ditas climáticas. Os resultados apontam ainda para a significativa importância dos processos geoquímicos na evolução do modelado local. Desse modo, é possível verificar, na Depressão de Gouveia, aspectos evolutivos do relevo preconizados por diversas teorias de evolução do modelado. No entanto, e apesar da presença desses aspectos, os resultados obtidos não permitem filiar, de forma inequívoca, a evolução do relevo da área investigada a nenhuma dessas teorias.

\section{AGRADECIMENTOS}

As pesquisas que permitiram a realização desse trabalho foram desenvolvidas graças ao apoio financeiro da FAPEMIG, CNPq, CAPES e FINEP, bem como ao apoio do Centro de Desenvolvimento de Tecnologia Nuclear-CDTN, na pessoa dos técnicos Fábio Câmara e Marta Avelar.

\section{REFERÊNCIASBIBLIOGRÁFICAS}

Davis W. M. 1898. O Ciclo Geográfico. São Paulo: Seleção de Textos: Davis \& Martone. AGB 19: 9-27.

King C. L. 1953. Canons of Landscape Evolution. Bulletin of the Geology Society of America. 64 (7): 721-732.

Millot G. 1980. Les grands aplainissements des soeles continentaux dans les pays tropicaux et desertiques. Mém . H. Ser. Soc. Géol. De France, v.10: 295-305.

Salgado A. A. R. 2002. Desnudação geoquímica e Evolução do Relevo no Espinhaço Meridional. Belo Horizonte: IGC/UFMG. Dissertação de Mestrado. 189pp.

Summerfield M. A. 1991. Global Geomorphology: an introduction of the study of landforms. Essex, Longman Scientific \& Technical: 129-144, 163-203, 371-395, 457-478.

Tardy Y. 1969. Geochimie dês Alterations Étude des arènes et dês eaux de quelques massifs cristallins D'Éurope et D'Áfrique. Ser. Soc. Géol. D’ Alsace et Lorraine. N 31. 199 pp. 